\title{
Effect of the particle size of pear pomace on the quality of enriched layer and sponge cakes
}

Andrés F. Rocha-Parra ${ }^{1}$, Mayara Belorio ${ }^{3}$, Pablo D. Ribotta ${ }^{2}$, Cristina Ferrero $^{1}$, Manuel Gómez ${ }^{3 *}$.

${ }^{1}$ CIDCA, Facultad de Ciencias Exactas, CCT La Plata (CONICET), Universidad Nacional de La Plata, 47 y 116, 1900 La Plata, Argentina.

${ }^{2}$ CONICET, Facultad de Ciencias Agropecuarias, Universidad Nacional de Córdoba, Av. Valparaíso s/n, 5000 Córdoba, Argentina.

${ }^{3}$ Food Technology Area. College of Agricultural Engineering. University of Valladolid, 34004 Palencia, Spain.

*Corresponding author e-mail: andresfelipe2484@gmail.com

\begin{abstract}
Pear pomace (PP) is a by-product of the fruit industry with a high content of fiber. Its potential as an ingredient at $15 \%$ or $30 \%$ level for sponge and layer cakes was investigated. Three PP powders with different particle sizes (fine, medium and coarse) were obtained. Microstructure, density and viscosity were evaluated in batter, and specific volume, texture and color in the final product. When PP was added, less uniformity in bubble distribution was observed in batters, particularly at higher particle sizes. Cake specific volume significantly diminished with increasing amounts of PP. For sponge cakes, the decrease in specific volume was the highest for the finest particle size of PP. In general, increasing PP addition increased hardness and reduced elasticity, cohesiveness and resilience but the effect depended on the particle size. In general, better textural attributes were obtained with medium and coarse particle sizes. These results indicate that PP of an adequate particle size could be a promising fiber source for different cake formulations.
\end{abstract}

Keywords: pear, bagasse, sponge cake, layer cake, batter 


\section{Introduction}

Pear (Pyrus communis) is one of the most consumed fruits worldwide. Global production reached up to 27 million tons in 2016, the Asiatic region being the main producer (79\% of the total production). The process for obtaining juice or pear paste generates a considerable amount of pomace (bagasse), a by-product consisting of seeds, peel and cores with high water content that can be a significant environmental contaminant. To diminish this environmental impact and, at the same time, take advantage of the valuable aspects of this by-product, increasing research has been conducted. Normally, the juice process removes up to $85 \%$ of the fresh weight of the fruits. The residue still contains high amount of water and different non-digestible polysaccharides and lignin. Fiber content in pear pomace (PP) was found to be close to $35 \%$, being mainly insoluble fiber (Grigelmo-Miguel \& Martín-Belloso, 1999; Martín-Cabrejas et al.,1995). Among the components of the PP fiber, Klason lignin (19.66\% d.b.), cellulose $(32.43 \%$ d.b.) and hemicelluloses $(20.22 \%$ d.b.) have been reported (Rabetafika et al., 2014). It has been found that besides dietary fiber, pear pomace contains valuable substances with healthy effects on our metabolism, such as phenolic compounds and organic acids, among others (Rhyuet al., 2014). Because of its composition, PP has been investigated with different medical objectives. The combined extracts from PP and Garcinia cambogia (Malabar tamarind) were reported to have inhibitory effects on adipogenesis with the consequent potential utility as obesity inhibitors (Sharma et al., 2018). Aqueous extracts from PP were also used to depress lipid peroxidation in liver and as a liver protector in rats fed with a high lipidic diet (You et al., 2017a). You et al. (2017b) also tried ethanolic extracts from PP to improve the sensibility to insulin in vitro, and in vivo with animal models that were fed with a diet with high lipid content. It was also found that the insoluble dietary fiber extracted from PP can improve gut microbiota, thus preventing obesity in rats fed with high lipid diets (Chang et al., 2017).

In spite of these findings, the use of PP in food technology has been scarcely explored in contrast with other fruit by-products such as apple pomace. Pear pomace has been used in the development of cereal bars (Bchir et al., 2018) and breads (Bchir et al., 2014). So far, PP has not been studied as an ingredient for enriching other related formulations such as sponge and layer cakes. Cakes may be good carriers for these by-products, thus providing valuable healthy components to the diet (Jung et al., 2015; Younas et al., 2015; Bajerska et al., 2016; Khalifa et al., 2016; Mildner-Szkudlarz et al., 2016). However, it must be taken into account 
that the physical properties of pomace and mainly its particle size may influence the technological quality of the final product (Dhen et al., 2016; Majzoobi et al., 2016; De la Hera et al., 2013a). The objectives of the present work were to assess ground PP as a rich fiber ingredient for sponge and layer cakes. Two levels of wheat flour replacement, $15 \%$ and $30 \%$ (w/w, flour basis), and three particle sizes of ground PP (fine, medium, coarse) were used. The microstructure, density and viscosity of batters were evaluated, and the cakes were characterized by specific volume, texture and color.

\section{Materials and methods}

\subsection{Materials}

Pear pomace was provided by the juice industry Jugos SA (Villa Regina, Río Negro, Argentina), wheat flour (WF) (11.42 g/100 g moisture; $10.43 \mathrm{~g} / 100 \mathrm{~g}$ protein) was supplied by Harinera Castellana S.L. (Medina del Campo, Valladolid, Spain), and white sugar by AB Azucarera Iberia (Valladolid, Spain). Additionally, for sponge cakes: skimmed milk powder (Sveltesse, Nestlé, Llobregat, Spain), liquid pasteurized egg (Ovopack, Álvarez Camacho, S.L., Sevilla, Spain), emulsifier SuperMixo T500 (Puratos, Gerona, Spain) and for layer cakes: UHT whole milk (President, Lactalis Food Service Iberia, S.L.U., Madrid, Spain), refined sunflower oil (Langosta, F. Faiges, S.L., Daimiel, Ciudad Real, Spain), baking powder "25 × 1" (Puratos, Gerona, Spain) were used.

\subsection{Methods}

\subsubsection{Pear pomace preparation and characterization}

Pear pomace was dried in a forced convection oven (ESTIGIA, La Plata, Argentina) at $50{ }^{\circ} \mathrm{C}$ up to a moisture level below $10 \% \mathrm{w} / \mathrm{w}$. It was then ground with a sieve size of $0.75 \mathrm{~mm}$ (Cross Beater Mill, PULVERISETTE 16, Haan, Germany). The proximal composition of PP was $(\mathrm{n}=2$, mean $\pm \mathrm{SD}$ ): moisture, $8.02 \pm 0.14 \mathrm{~g}$ (AOAC 964.22, 1990); protein, $4.78 \pm 0.01 \mathrm{~g}$ (AACC 46-12, 2000); ash, 1.06 $\pm 0.01 \mathrm{~g}$ (AACC 8-1, 2000), total dietary fiber, $66.55 \pm 0.64 \mathrm{~g}$ (AOAC 991.4, 1990); fat, 1.90 $\pm 0.08 \mathrm{~g}$ (AOAC 920.39, 1990) and carbohydrates different from fiber, $17.69 \mathrm{~g}$ (calculated by difference). After being sterilized at $121{ }^{\circ} \mathrm{C}$ for $20 \mathrm{~min}$ to eliminate the natural flora (yeasts and molds), PP was reground using two different ring sieves (0.5 mm and $0.2 \mathrm{~mm}$ ) (Ultra-Centrifugal Mill, Retsch, ZM 200, Haan, Germany). The particle size of PP was determined as the volume fraction-length mean diameter $(\mathrm{d}(4,3))$ using a Malvern Mastersizer 3000 E (Malvern Instruments Ltd., Worcestershire, UK). The 
three final products were named according to the sieve used as PP750, PP500 and PP200.

Color measurements were performed with a surface spectrophotometer Minolta CN-508i (Minolta, Co. Ltd, Tokyo, Japan) using the D65 illuminant with the 2-standard observer. For this purpose, $1.5 \mathrm{~g}$ of each powder was weighed in a glass capsule $2 \mathrm{~cm}$ high and $9 \mathrm{~cm}$ in diameter. The measurements were made in duplicate, and the results were expressed in the CIE L*, $a^{*}, b^{*}$ color space.

Water holding capacity (WHC) and water binding capacity (WBC) were determined according to AACC (2012) methods 88-04 and 56-30.01, respectively. WHC is the amount of water retained by the sample when no stress is applied. WBC is the amount of water retained by the sample under low-speed centrifugation. Assays were performed in duplicate.

The oil absorption capacity (OAC) is expressed as grams of oil bound per gram of sample on dry basis. It was evaluated according to De la Hera et al. (2013b). Three replicates were performed for each sample.

\subsubsection{Cake formulation and preparation}

Formulations for sponge and layer cakes were based on a previous work by Dhen et al. (2016). They are shown in Table 1. Flow sheets in Figures 1 and 2 schematize the steps for sponge and layer cake preparation, respectively. Weight losses by cooking were $10.2 \%$ and $17 \%$ for control layer and control sponge cakes, respectively. When adding PP, losses ranged from $7.1 \%$ to $10.7 \%$ for layer cakes. For sponge cakes the losses were higher and varied within a narrower range, $15.1-17.6 \%$.

\subsubsection{Batter properties}

Batter properties were measured immediately after being prepared, on two independent batters of each formulation. For density measurements, a pycnometer Elcometer 1800 (Elcometer, Manchester, UK) was used. Batter viscosity was measured after 2 min stirring at $160 \mathrm{rpm}\left(30^{\circ} \mathrm{C}\right)$ with a Rapid Viscoanalyzer (RVA-4) (Newport Scientific model 4-SA, Warriewood, Australia) according to Dhen et al. (2016).

A DM750 microscope (Leica Microsystems, Wetzlar, Germany) with 20X magnification, and fitted with an EC3 video camera and LAS EZ software (Leica Microsystems, Wetzlar, Germany) was used for performing the qualitative analysis of the batter microstructure. A drop of sample was placed on a slide, covered and compressed under a $1 \mathrm{~kg}$ weight to obtain a uniform thickness. Three micrographs of different fields of each sample were taken. 


\subsubsection{Cake technological quality}

Quality was assessed $24 \mathrm{~h}$ after baking. Cake volume was determined using a Volscan Profiler volume analyzer (Stable Micro Systems, Surrey, UK).

The texture Profile Analysis (TPA) was performed with a TA. XT2 Texture Analyzer (Stable Micro Systems, Godalming, U.K.) using a cylindrical aluminum probe (25 mm diameter). Two compression cycles at a speed of $2 \mathrm{~mm} / \mathrm{s}$ were accomplished up to $50 \%$ of the original sample height. Four cakes were prepared per formulation; measurements were carried out on two slices $(20 \mathrm{~mm}$ thick) obtained from the center of each cake. Hardness, cohesiveness, springiness and resilience were calculated from the curves.

The color of cake slices (crumb and crust) was measured with a surface spectrophotometer Minolta CN-508i (Minolta, Co. LTD, Tokyo, Japan) using the D65 illuminant with the 2standard observer. With $\mathrm{L}^{*}, \mathrm{a}^{*}$ and $\mathrm{b}^{*}$ parameters, the global color difference $(\Delta \mathrm{E})$ between the sample (s) and the control (c) was calculated as follows:

$$
\Delta E=\sqrt{\left(L_{s}^{*}-L_{c}^{*}\right)^{2}+\left(a_{s}^{*}-a_{c}^{*}\right)^{2}+\left(b_{s}^{*}-b_{c}^{*}\right)^{2}}
$$

Two cakes were prepared for each formulation, and measurements were performed on both sides of two central slices. Three points were measured on the crust.

\subsubsection{Sensory analysis}

For hedonic sensory evaluation, 80 cake usual consumer volunteers participated in the assay conducted in the Agricultural Engineering College (Palencia, Spain). The following attributes were evaluated on the basis of acceptance: appearance, odor, taste, texture and overall acceptability. The scale ranged from "dislike extremely" (score 1) to "like extremely" (score 9). All samples were analyzed $24 \mathrm{~h}$ after baking.

\subsubsection{Statistical analysis}

Statgraphics Centurion XVI software (Statpoint Technologies, Warrenton, USA) was used. Analysis of variance (ANOVA) was applied and Tukey's HSD was used to determine significant differences among means, within $95 \%$ confidence intervals.

\section{Results and Discussion}

\subsection{Pear pomace properties}


As shown in Table 2, WHC values were more than three times higher than those of WF and the smaller the PP particle size, the higher WHC. De la Hera et al. (2013c), who obtained similar trends for rice flour particles, suggested that this behavior is related to the increasing total surface when particles are ground to smaller sizes. In contrast, no significant differences were obtained among WBC values as a function of particle size though the values were twice higher than WF value. In all cases, OAC was significant and slightly higher for samples with PP than for WF, but no clear trend was evident as a function of the particle size.

With respect to color parameters, $\mathrm{L}^{*}$ (luminosity) of PP was lower than $\mathrm{L}^{*}$ of WF, but it was not significantly affected by the particle size. Parameters a* (green-red) and b* (blue-yellow) were higher than those of WF. The finest fraction had higher values of $b^{*}$ and lower values of $\mathrm{a}^{*}$. These differences between fine and coarse fractions are probably due to the higher exposed surface of the finest particles, making the powder more susceptible to oxidative reactions, as suggested in previous work (Martinez et al., 2014). Pomace is susceptible to reactions leading to brownish pigments as final products. Maillard reaction occurs between reducing sugars and proteins (Martins et al., 2001) and the oxidative enzymatic reaction can also proceed until the enzyme is inactivated by heating (Yoruk \& Marshall, 2003).

\subsection{Batter properties}

Batters were analyzed by optical microscopy (Figures 3 and 4). Comparing the micrographs of both batters without PP (Figures 3a and 4a), much higher aeration can be observed in sponge batter, evidenced by the presence of bubbles of different sizes. Layer cake batter presents a lower amount of air bubbles and a more continuous aspect than sponge batter. All the formulations with PP show a more irregular distribution of components, particularly for the highest particle sizes and levels of PP. Particularly for sponge cake batter with the finest PP powder, at both levels of replacement, a great amount of smaller bubbles can be observed uniformly surrounding the greater bubbles. Large bubbles can be appreciated in the systems with the coarsest particle size. For gluten-free rice cakes De la Hera et al. (2013a) reported that finer particle sizes led to finer bubbles.

In Table 3, the main physical characteristics of batters corresponding to layer and sponge cakes are shown. The batter density is an indicator of the amount of incorporated air and depends on surface tension, viscosity and the type and speed of mixing (Hedayati \& Terani, 2018; Ronda et al., 2011). The higher aeration of the sponge batter resulted in lower densities than in layer cake batter (threefold lower). However, no significant differences were 
found among densities of batters with different levels of replacement and PP particle size. Similar trends were reported by Segundo et al. (2017) who formulated sponge and layer cakes with $15 \%$ and $30 \%$ of replacement of WF by green banana flour of different particles sizes.

For sponge batters the level of PP had a significant effect on viscosity (Table 3). The highest viscosity values corresponded to the formulations with 15\% PP and with the largest particle sizes, PP750 and PP500. On the other hand, for layer cake batters, the highest viscosity corresponded to the sample with 30\% PP of the finest particle size (PP200).

Though no significant differences were found, sponge cake batters with $30 \%$ PP exhibited a trend to lower viscosities than batters with $15 \% \mathrm{PP}$, probably because the highest level of replacement led to less uniform, weaker foams, more susceptible to collapse. Conversely, for layer cake batters, more uniformly structured, the viscosities of batters with $30 \%$ PP were significantly higher than those with $15 \%$ PP and the control. At both levels of replacement, smaller particle sizes led to higher viscosities (Table 2). Since viscosity is related to the interaction among components within the system, this could suggest that the smallest particles are able to interact in a more efficient way, resulting in more friction and resistance to flow. Particularly, the higher WHC would indicate a stronger interaction with water when particles are smaller (Table 2). In spite of this, batter viscosity did not significantly correlate with WHC nor WBC ( $>00.05)$. Similar trends were found by Dhen et al. (2016) for batters of gluten-free cakes with $15 \%$ and $30 \%$ replacement of soy flour of different particle sizes. These authors also found the highest viscosity values for layer batters with $30 \%$ replacement and for sponge batters with $15 \%$ replacement. The incorporation of intermediate and coarse soy flours reduced the amount of air in the batter, leading to less stability. They associated the observed differences with the amount and way of air incorporation and the chemical composition of flour.

\subsection{Cake properties}

In Table 4, the values of specific volume and color parameters are shown. Specific volumes were higher for sponge cakes than for layer cakes, and the values of cakes with PP were always lower than those of their respective controls without PP. These trends are coincident with previous reports where sponge and layer cakes are compared (Dhen et al., 2016; Segundo et al., 2017). In all cases, specific volumes diminished when the amount of PP increased. The specific volume is linked with the size and distribution of bubbles. Small bubbles are more stable and less air is lost during baking, thus leading to higher volumes. An 
intermediate batter viscosity is necessary to attain a good bubble expansion: high viscosities hinder expansion and lower viscosities facilitate gas losses (Turabi et al., 2008; Ronda et al., 2009). For layer cakes, significant negative correlations $(\mathrm{p}<0.05)$ were found between the specific volume of the cake and the batter viscosity at both levels of replacement.

Figure 5 shows typical transversal slices of sponge (upper images) and layer (lower images) cakes, compared with controls prepared with WF (left slices). It can be observed that sponge cakes with $30 \%$ replacement have a strongly diminished volume compared to the control, which is normally associated with more irregular and greater air bubbles. Similar trends were observed by Segundo et al. (2017).

Crust color did not exhibit clear trends, probably because the product surface is submitted to small temperature variations in the oven and the color is not uniform. For sponge cakes, $\mathrm{L}^{*}$ values of crust were lower than the control one for samples with $30 \% \mathrm{PP}$, but for layer cakes, all the samples with PP had lower L* than the control, and no significant differences were found among samples (Table 4). As crumb temperature does not exceed $100^{\circ} \mathrm{C}$ during baking, Maillard reaction is not favored and thus, it exhibits higher $\mathrm{L}^{*}$ values than crust and its color is more related to the ingredients. Due to the addition of PP, crumb color was darker, exhibiting more variation with respect to the control $(\Delta \mathrm{E})$ in cakes with $30 \% \mathrm{PP}$ than in cakes with 15\% PP. The darker color obtained with PP, particularly at the highest level of replacement, can be clearly noted (Figure 5).

The effect of particle size and level of PP on the main texture attributes of both types of cakes is shown in Figure 6. It can be observed that the highest level of replacement $(30 \%)$ led to harder, less elastic, less resilient and less cohesive crumbs for both types of formulations.

At $30 \%$ replacement, both layer and sponge cakes showed increasing hardness when the particle size decreased. At 15\% replacement, there was no marked effect of particle size. Springiness and resilience drastically diminished for both types of cakes when the level of replacement was $30 \%$, independently of the particle size used (no significant differences were found). Cohesiveness was also more affected at 30\% level of PP, and more drastically in the case of sponge cake. Normally, hardness is negatively correlated with specific volume; the more aerated the crumb (higher specific volumes) the lower the hardness (De la Hera et al., 2013a; Segundo et al., 2017). However, in the present work, no significant general correlation was found between specific volume and hardness. It has been demonstrated that hardness of crumb is not only related to the presence of air cells but also to the stiffness of cell walls (Attenburrow et al., 1989), strongly linked to bread composition. The presence of 
PP within cell walls can lead to a reinforcement and hardening of the crumb and thus to a lack of clear correlation between specific volume and hardness.

Sensory analysis was performed only with layer cakes. Sponge cakes are usually consumed with fillings or toppings that mask the sensory perception. Only cakes with $15 \%$ PP were tested because layer cakes with 30\% PP were excessively dark and bitter-tasting. Bitterness and astringency in fruits are due to the presence of polyphenols, substances that are also related to flesh browning; these characteristics can negatively affect the acceptance by the consumer (Hamauzu et al., 2007; Baia et al., 2009, Dinnella et al., 2011). Results are shown in Table 5. No significant differences were found among formulations with PP of different particle size. Odor and taste punctuations for cakes with PP were similar as for control layer cake. Appearance was significant but slightly less punctuated, ranging from $6.64 \pm 1.45$ to $6.83 \pm 1.36$, probably due to the lesser volume and darker color, as can be observed in Figure 5. Overall acceptability punctuation of cakes with PP did not exhibit significant differences with the control except for cakes with PP500, ranging between $6.79 \pm 1.32$ and $7.14 \pm 1.22$.

\section{Conclusions}

Pear pomace is an underutilized by-product from the fruit industry. It contains a remarkable amount of fiber (more than 66\%) which includes lignin, cellulose and hemicelluloses. Its composition explains both the hydrophilicity and hydrophobicity of this ingredient, reflected in the values of WHC, WBC and OAC. As it has been reported for other fruit pomaces, its use as ingredient may strongly affect the technological properties of foods, particularly of baked products. In the present work, the effect of three particle sizes of PP and two levels of replacement in two different types of cakes was evaluated. The batter of the sponge cake was highly aerated, and exhibited low density and viscosity instability. On the other hand, the layer cake batter was much less aerated, with a density higher than water and higher rheological stability. When PP was incorporated, the viscosity increased, much more markedly in layer cake batter at $30 \%$ replacement. After baking, sponge cakes presented higher specific volumes and more elastic and aerated crumbs than layer cakes. In both types of formulation, high levels of WF replacement (30\%) were detrimental to volume and texture for all particle sizes. At a lower level of PP (15\%), softer crumbs were obtained in sponge cakes, and elasticity and cohesiveness were not much different from the control values. Similarly, for layer cakes texture attributes were adequately maintained in all cases. The present work suggests that it is possible to use PP as a fiber-rich ingredient without much affecting the properties and acceptance of a cake product at $15 \%$ replacement. Though the 
effect of PP particle size on some properties was significant, it was not as influencing as the level of replacement. However, better textural attributes were obtained with medium and coarse particle sizes.

\section{Acknowledgements}

The authors acknowledge the financial support of the Spanish Ministry of Economy and Competitiveness (Project AGL2014-52928-C2-2-R) and the European Regional Development Fund (FEDER) and the University of La Plata (Projects 11/X661 and 11/X771) and CONICET from Argentina. The authors also want to acknowledge the pear pomace donation by Jugos SA of Rio Negro, Argentina.

\section{References}

Attenburrow, G. E., Goodband, R. M., Taylor, L. J., \& Lillford, P. J. (1989). Structure, mechanics and texture of a food sponge. Journal of Cereal Science, 9, 61-70.

Baia, J, Wuc, P., Mantheya, J., Goodnera, K., \& Baldwina,E. (2009) Effect of harvest maturity on quality of fresh-cut pear salad. Postharvest Biology and Technology, 51, $250-256$

Bajerska, J., Mildner-Szkudlarz, S., Górnaś, P., \& Seglina, D. (2016). The effects of muffins enriched with sour cherry pomace on acceptability, glycemic response, satiety and energy intake: A randomized crossover trial. Journal of the Science of Food and Agriculture, 96(7), 2486-2493.

Bchir, B., Jean-franc, T., Rabetafika, H. N., \& Blecker, C. (2018). Effect of pear apple and date fibres incorporation on the physico-chemical, sensory, nutritional characteristics and the acceptability of cereal bars. Food Science and Technology International, 24(3), 198-208.

Bchir, B., Rabetafika, H. N., Paquot, M., \& Blecker, C. (2014). Effect of Pear, Apple and Date Fibres from Cooked Fruit By-products on Dough Performance and Bread Quality. Food and Bioprocess Technology, 7(4), 1114-1127.

Chang, S., Cui, X., Guo, M., Tian, Y., Xu, W., Huang, K., \& Zhang, Y. (2017). Insoluble dietary fiber from pear pomace can prevent high-fat diet-induced obesity in rats mainly by improving the structure of the gut microbiota. Journal of Microbiology and Biotechnology, 27(4), 856-867. 
De la Hera, E., Gómez, M, \& Rosell, C.M. (2013b) Particle size distribution of rice flour affecting the starch enzymatic hydrolysis and hydration properties. Carbohydrate Polymers 98(1), 421-427.

De la Hera, E., Martinez, M., \& Gómez, M (2013c) Influence of flour particle size on quality of gluten-free rice bread. LWT - Food Science and Technology 54, 199-206.

De la Hera, E., Martinez, M., Oliete, B., \& Gómez, M. (2013a). Influence of Flour Particle Size on Quality of Gluten-Free Rice Cakes. Food and Bioprocess Technology, 6(9), $2280-2288$.

Dhen, N., Román, L., Ben Rejeb, I., Martínez, M. M., Garogouri, M., \& Gómez, M. (2016). Particle size distribution of soy flour affecting the quality of enriched gluten-free cakes. LWT - Food Science and Technology, 66, 179-185.

Dinnella, C., Recchia, A., Tuorila, H., \& Monteleone, E. (2011) Individual astringency responsiveness affects the acceptance of phenol-rich foods. Appetite, 56, 633-642

Grigelmo-Miguel, N., \& Martin-Belloso, O. (1999). Comparison of dietary fibre from byproducts of processing fruits and greens and from cereals. LWT - Food Science and Technology, 32(8), 503-508.

Hamauzu, Y., Forest, F., Hiramatsu, K. \& Sugimoto, M. (2007). Effect of pear (Pyrus communis L.) procyanidins on gastric lesions induced by $\mathrm{HCl} /$ ethanol in rats. Food Chemistry, 100, 255-263.

Hedayati, S., \& Tehrani, M. M. (2018). Effect of total replacement of egg by soymilk and lecithin on physical properties of batter and cake. Food Science and Nutrition, (March), $1-8$.

Jung, J., Cavender, G., \& Zhao, Y. (2015). Impingement drying for preparing dried apple pomace flour and its fortification in bakery and meat products. Journal of Food Science and Technology, 52(9), 5568-5578.

Khalifa, I., Barakat, H., El-Mansy, H. A., \& Soliman, S. A. (2016). Influencing of guava processing residues incorporation on cupcake characterization 2016.pdf. Journal of Nutrition \& Food Sciences, 6(4), 1-8.

Majzoobi, M., Poor, Z. V., Jamalian, J., \& Farahnaky, A. (2016). Improvement of the quality of gluten-free sponge cake using different levels and particle sizes of carrot pomace powder. International Journal of Food Science and Technology, 51(6), 1369-1377.

Martín-Cabrejas, M. A., Esteban, R. M., López-Andreu, F. J., Waldron, K., \& Selvendran, R. R. (1995). Dietary Fiber Content of Pear and Kiwi Pomaces. Journal of Agricultural and Food Chemistry, 43(3), 662-666. 
Martinez, M.M, Calviño, A, Rosell CM , \& Gómez, M. (2014) Effect of different extrusion treatments and particle size distribution on the physicochemical properties of rice flour. Food and Bioprocess Technology 7, 2657-2665.

Martins, S.I.F.S.,Jongen; W.M.F \& van Boekel. (2001) A review of Maillard reaction in food and implications to kinetic modelling. Trends in Food Science \& Technology 11, 364 373.

Mildner-Szkudlarz, S., Bajerska, J., Górnaś, P., Segliņa, D., Pilarska, A., \& Jesionowski, T. (2016). Physical and Bioactive Properties of Muffins Enriched with Raspberry and Cranberry Pomace Powder: A Promising Application of Fruit By-Products Rich in Biocompounds. Plant Foods for Human Nutrition, 71(2), 165-173.

Rabetafika, H. N., Bchir, B., Blecker, C., Paquot, M., \& Wathelet, B. (2014). Comparative study of alkaline extraction process of hemicelluloses from pear pomace. Biomass and Bioenergy, 61(0), 254-264.

Rhyu, J., Kim, M. S., You, M. K., Bang, M. A., \& Kim, H. A. (2014). Pear pomace water extract inhibits adipogenesis and induces apoptosis in 3T3-L1 adipocytes. Nutrition Research and Practice, 8(1), 33-39.

Ronda, F., Gómez, M., Caballero, P.A., Oliete, B. \& Blanco, C.A. (2009). Improvement of quality of gluten-free layer cakes. Food Science and Technology International, 15, 193202.

Ronda, F., Oliete, B., Gómez, M., Caballero, P. A., \& Pando, V. (2011). Rheological study of layer cake batters made with soybean protein isolate and different starch sources. Journal of Food Engineering, 102(3), 272-277.

Segundo, C., Román, L., Gómez, M., \& Martínez, M. M. (2017). Mechanically fractionated flour isolated from green bananas (M. cavendishii var. nanica) as a tool to increase the dietary fiber and phytochemical bioactivity of layer and sponge cakes. Food Chemistry, $219,240-248$.

Sharma, K., Kang, S., Gong, D., Oh, S.-H., Park, E.-Y., Oak, M.-H., \& Yi, E. (2018). Combination of Garcinia cambogia extract and pear pomace extract additively suppresses adipogenesis and enhances lipolysis in 3T3-L1 cells. Pharmacognosy Magazine, 14(54), 220-226.

Turabi, E., Sumnu, G. \& Sahin, S. (2008). Rheological properties and quality of rice cakes formulated with different gums and an emulsifier blend. Food Hydrocolloids, 22, 305312.

Yoruk, R. \& Marshall, M.R. (2003) Physicochemical Properties and Function of Plant 
Polyphenol Oxidase: A Review. Journal of Food Biochemistry 27 361-422

You, M.-K., Jin, R., \& Kim, H.-A. (2017a). Pear pomace water extract suppresses hepatic lipid peroxidation and protects against liver damage in rats fed a high fat / cholesterol diet. Food Science and Biotechnology, 26(3), 801-806.

You, M.-K., Kim, H.-J., Rhyu, J., \& Kim, H.-A. (2017b). Pear pomace ethanol extract improves insulin resistance through enhancement of insulin signaling pathway without lipid accumulation. Nutrition Research and Practice, 11(3), 198.

Younas, M. B., Rakha, A., Sohail, M., Rashid, S., \& Ishtiaq, H. (2015). Physicochemical and sensory assessment of apple pomace enriched muffins. Pakistan Journal of Food Sciences, 25(4), 224-234.

Table 1. Formulations for sponge and layer cakes (one batch)

\begin{tabular}{ccccccc}
\hline & \multicolumn{3}{c}{ Sponge cake } & \multicolumn{3}{c}{ Layer cake } \\
\cline { 2 - 7 } & C & 15 & 30 & C & 15 & 30 \\
\hline Wheat flour & 245 & 208.25 & 171.50 & 350 & 297.50 & 245 \\
Pear pomace & $\mathbf{0}$ & $\mathbf{3 6 . 7 5}$ & $\mathbf{7 3 . 5 0}$ & $\mathbf{0}$ & $\mathbf{5 2 . 5 0}$ & $\mathbf{1 0 5}$ \\
Sugar & 240.5 & 240.5 & 240.5 & 315 & 315 & 315 \\
Milk & ---- & ---- & ---- & 210 & 210 & 210 \\
Powdered milk & 25 & 25 & 25 & ---- & ---- & ---- \\
Liquid egg & 344 & 344 & 344 & 175 & 175 & 175 \\
Sunflower oil & ---- & ---- & ---- & 105 & 105 & 105 \\
Emulsifier & 14 & 14 & 14 & ---- & ---- & ---- \\
Baking powder & ---- & ---- & ---- & 10.5 & 10.5 & 10.5 \\
Water & 55 & 55 & 55 & ---- & ---- & ---- \\
\hline
\end{tabular}

Formulations are based on Dhen et al., 2016

Table 2 Physical properties of PP ground to different particle sizes

\begin{tabular}{llllcccl}
\hline & $\mathbf{d ~ ( 4 ; 3 )}(\boldsymbol{\mu m})$ & \multicolumn{1}{c}{ WHC $^{*}$} & \multicolumn{1}{c}{ WBC $^{*}$} & OAC** $^{* *}$ & \multicolumn{1}{c}{$\mathbf{L}^{*}$} & \multicolumn{1}{c}{$\mathbf{a}^{*}$} & \multicolumn{1}{c}{$\mathbf{b}^{*}$} \\
\hline WF & $95 \pm 1 \mathrm{a}$ & $1.53 \pm 0.01 \mathrm{a}$ & $1.94 \pm 0.02 \mathrm{a}$ & $2.02 \pm 0.02 \mathrm{a}$ & $89.7 \pm 1.1 \mathrm{~b}$ & $-0.17 \pm 0.01 \mathrm{a}$ & $8.4 \pm 0.3 \mathrm{a}$ \\
PP750 & $455 \pm 29 \mathrm{~d}$ & $4.7 \pm 0.1 \mathrm{~b}$ & $4.1 \pm 0.1 \mathrm{~b}$ & $2.23 \pm 0.02 \mathrm{c}$ & $52.0 \pm 0.5 \mathrm{a}$ & $6.58 \pm 0.09 \mathrm{c}$ & $15.8 \pm 0.4 \mathrm{~b}$ \\
PP500 & $312 \pm 11 \mathrm{c}$ & $5.0 \pm 0.3 \mathrm{~b}$ & $4.0 \pm 0.1 \mathrm{~b}$ & $2.42 \pm 0.03 \mathrm{~d}$ & $54.4 \pm 0.3 \mathrm{a}$ & $6.45 \pm 0.01 \mathrm{c}$ & $16.5 \pm 0.1 \mathrm{~b}$ \\
PP200 & $203.5 \pm 0.7 \mathrm{~b}$ & $5.74 \pm 0.02 \mathrm{c}$ & $4.08 \pm 0.06 \mathrm{~b}$ & $2.11 \pm 0.01 \mathrm{~b}$ & $55.6 \pm 2.5 \mathrm{a}$ & $5.8 \pm 0.2 \mathrm{~b}$ & $17.70 \pm 0.06 \mathrm{c}$ \\
\hline
\end{tabular}

*g water/g solid ** g oil/g solid

mean \pm standard deviations Different letters within the same column indicate significant differences 
Table 3. Batter properties: density and viscosity

\begin{tabular}{llllll}
\hline & \multicolumn{2}{c}{ Sponge cake batter } & \multicolumn{2}{c}{ Layer cake batter } \\
\cline { 2 - 6 } & $\begin{array}{c}\text { Density } \\
\left(\mathrm{g} / \mathrm{cm}^{3}\right)\end{array}$ & $\begin{array}{c}\text { Viscosity }(\mathrm{cP}) \\
\text { at } 2 \mathrm{~min}\end{array}$ & $\begin{array}{c}\text { Density } \\
\left(\mathrm{g} / \mathrm{cm}^{3}\right)\end{array}$ & $\begin{array}{c}\text { Viscosity }(\mathrm{cP}) \\
\text { at } 2 \mathrm{~min}\end{array}$ \\
\hline Control & $0.36 \pm 0.01 \mathrm{a}$ & $2747 \pm 500 \mathrm{ab}$ & $1.06 \pm 0.01 \mathrm{a}$ & $4321 \pm 5 \mathrm{a}$ \\
\hline \multirow{2}{*}{ PP750 } & $\mathbf{1 5 \%}$ & $0.35 \pm 0.01 \mathrm{a}$ & $4152 \pm 57 \mathrm{ab}$ & $1.05 \pm 0.02$ a & $5781 \pm 57 \mathrm{ab}$ \\
\cline { 2 - 6 } & $\mathbf{3 0 \%}$ & $0.34 \pm 0.02 \mathrm{a}$ & $2607 \pm 129 \mathrm{a}$ & $1.07 \pm 0.02$ a & $10242 \pm 289 \mathrm{c}$ \\
\hline \multirow{2}{*}{ PP500 } & $\mathbf{1 5 \%}$ & $0.32 \pm 0.01 \mathrm{a}$ & $4888 \pm 736 \mathrm{~b}$ & $1.05 \pm 0.03$ a & $6409 \pm 448 \mathrm{ab}$ \\
\hline \multirow{2}{*}{$\mathbf{3 0 \%}$} & $0.36 \pm 0.01 \mathrm{a}$ & $3004 \pm 1027 \mathrm{ab}$ & $1.10 \pm 0.03$ a & $15015 \pm 1761 \mathrm{~d}$ \\
\hline \multirow{2}{*}{$\mathbf{1 5 \%}$} & $0.36 \pm 0.01 \mathrm{a}$ & $3109 \pm 566 \mathrm{ab}$ & $1.06 \pm 0.02$ a & $8115 \pm 88 \mathrm{bc}$ \\
\cline { 2 - 6 } & $\mathbf{3 0 \%}$ & $0.36 \pm 0.02 \mathrm{a}$ & $2852 \pm 352 \mathrm{ab}$ & $1.11 \pm 0.02$ a & $20500 \pm 165 \mathrm{e}$ \\
\hline
\end{tabular}

mean \pm SD Different letters within the same column and cake type indicate significant differences $(\mathrm{p}<0.05)$

Table 4. Specific volume and color parameters of sponge and layer cakes with PP

\begin{tabular}{|c|c|c|c|c|c|c|}
\hline \multicolumn{7}{|c|}{ Sponge cake } \\
\hline & & \multirow{2}{*}{$\begin{array}{l}\text { Sp volume } \\
\left(\mathrm{cm}^{3} / \mathrm{g}\right)\end{array}$} & \multicolumn{2}{|c|}{ Crust } & \multicolumn{2}{|c|}{ Crumb } \\
\hline & & & $\mathrm{L}$ & $\Delta \mathrm{E}$ & $\mathrm{L}$ & $\Delta \mathrm{E}$ \\
\hline Control & & $4.13 \pm 0.11 \mathrm{c}$ & $39.07 \pm 4.65 \mathrm{~cd}$ & 0 & $79.56 \pm 1.11 \mathrm{c}$ & 0 \\
\hline \multirow{2}{*}{ PP750 } & $15 \%$ & $3.66 \pm 0.08 \mathrm{~b}$ & $41.32 \pm 2.55 \mathrm{~cd}$ & $5.38 \pm 0.99 \mathrm{ab}$ & $61.20 \pm 1.30 \mathrm{~b}$ & $18.94 \pm 1.66 \mathrm{a}$ \\
\hline & $30 \%$ & $2.54 \pm 0.11 \mathrm{a}$ & $32.67 \pm 2.56 \mathrm{ab}$ & $8.20 \pm 1.77 \mathrm{bc}$ & $41.40 \pm 1.40 \mathrm{a}$ & $38.91 \pm 1.77 \mathrm{~b}$ \\
\hline \multirow{2}{*}{ PP500 } & $15 \%$ & $3.80 \pm 0.10 \mathrm{bc}$ & $41.61 \pm 2.04 \mathrm{~cd}$ & $5.68 \pm 3.02 \mathrm{ab}$ & $60.81 \pm 1.52 \mathrm{~b}$ & $19.40 \pm 2.10 \mathrm{a}$ \\
\hline & $30 \%$ & $2.44 \pm 0.04 \mathrm{a}$ & $29.72 \pm 2.16 \mathrm{a}$ & $10.51 \pm 1.19 \mathrm{c}$ & $41.96 \pm 3.45 \mathrm{a}$ & $38.65 \pm 3.16 \mathrm{~b}$ \\
\hline \multirow{2}{*}{ PP200 } & $15 \%$ & $3.96 \pm 0.15 \mathrm{bc}$ & $43.15 \pm 2.49 \mathrm{~d}$ & $6.55 \pm 1.65 \mathrm{ab}$ & $59.45 \pm 1.62 \mathrm{~b}$ & $20.85 \pm 2.19 \mathrm{a}$ \\
\hline & $30 \%$ & $2.81 \pm 0.44 \mathrm{a}$ & $37.82 \pm 3.64 \mathrm{bc}$ & $4.14 \pm 0.70 \mathrm{a}$ & $44.16 \pm 4.05 \mathrm{a}$ & $36.74 \pm 4.38 \mathrm{~b}$ \\
\hline \multicolumn{7}{|c|}{ Layer cake } \\
\hline & & \multirow{2}{*}{$\begin{array}{l}\text { Sp volume } \\
\left(\mathrm{cm}^{3} / \mathrm{g}\right)\end{array}$} & \multicolumn{2}{|c|}{ Crust } & \multicolumn{2}{|c|}{ Crumb } \\
\hline & & & $\mathrm{L}$ & $\Delta \mathrm{E}$ & $\mathrm{L}$ & $\Delta \mathrm{E}$ \\
\hline Control & & $2.62 \pm 0.02 \mathrm{e}$ & $55.13 \pm 4.72 \mathrm{~b}$ & 0 & $66.89 \pm 4.13 \mathrm{~d}$ & 0 \\
\hline \multirow{2}{*}{ PP750 } & $15 \%$ & $2.43 \pm 0.04 \mathrm{~d}$ & $41.96 \pm 1.78 \mathrm{a}$ & $16.99 \pm 4.77 \mathrm{a}$ & $53.83 \pm 1.16 \mathrm{c}$ & $13.22 \pm 3.66 \mathrm{a}$ \\
\hline & $30 \%$ & $2.05 \pm 0.03 \mathrm{~b}$ & $39.95 \pm 1.44 \mathrm{a}$ & $20.83 \pm 4.15 \mathrm{a}$ & $45.79 \pm 0.65 \mathrm{a}$ & $22.40 \pm 3.97 \mathrm{bc}$ \\
\hline \multirow{2}{*}{ PP500 } & $15 \%$ & $2.45 \pm 0.02 \mathrm{~d}$ & $39.04 \pm 2.04 \mathrm{a}$ & $16.89 \pm 4.74 \mathrm{a}$ & $50.75 \pm 1.65 \mathrm{~b}$ & $16.96 \pm 5.07 \mathrm{ab}$ \\
\hline & $30 \%$ & $1.98 \pm 0.04 \mathrm{~b}$ & $40.52 \pm 1.22 \mathrm{a}$ & $19.33 \pm 4.93 \mathrm{a}$ & $44.90 \pm 0.78 \mathrm{a}$ & $23.34 \pm 4.69 \mathrm{bc}$ \\
\hline \multirow{2}{*}{ PP200 } & $15 \%$ & $2.30 \pm 0.02 \mathrm{c}$ & $43.30 \pm 0.78 \mathrm{a}$ & $16.57 \pm 4.42 \mathrm{a}$ & $52.27 \pm 0.39 \mathrm{bc}$ & $15.86 \pm 4.27 \mathrm{a}$ \\
\hline & $30 \%$ & $1.65 \pm 0.06 \mathrm{a}$ & $42.02 \pm 1.66 \mathrm{a}$ & $18.03 \pm 4.65 \mathrm{a}$ & $45.16 \pm 0.98 \mathrm{a}$ & $23.18 \pm 4.66 \mathrm{c}$ \\
\hline
\end{tabular}

mean \pm SD Different letters within the same column and cake type indicate significant differences $(\mathrm{p}<0.05)$ 
Table 5. Punctuation of sensory attributes of layer cakes with $15 \%$ PP

\begin{tabular}{|l|c|c|c|c|c|}
\hline & Appearance & Odor & Texture & Taste & $\begin{array}{c}\text { Overall } \\
\text { acceptability }\end{array}$ \\
\hline Control & $7.71 \pm 1.15 \mathrm{~b}$ & $7.18 \pm 1.45 \mathrm{a}$ & $7.28 \pm 1.41 \mathrm{~b}$ & $7.28 \pm 1.46 \mathrm{a}$ & $7.50 \pm 1.19 \mathrm{~b}$ \\
\hline PP750 & $6.78 \pm 1.36 \mathrm{a}$ & $7.22 \pm 1.23 \mathrm{a}$ & $6.74 \pm 1.54 \mathrm{ab}$ & $6.98 \pm 1.53 \mathrm{a}$ & $7.09 \pm 1.14 \mathrm{ab}$ \\
\hline PP500 & $6.64 \pm 1.45 \mathrm{a}$ & $6.70 \pm 1.45 \mathrm{a}$ & $6.60 \pm 1.58 \mathrm{a}$ & $6.78 \pm 1.68 \mathrm{a}$ & $6.79 \pm 1.32 \mathrm{a}$ \\
\hline PP200 & $6.83 \pm 1.36 \mathrm{a}$ & $7.04 \pm 1.47 \mathrm{a}$ & $6.91 \pm 1.46 \mathrm{ab}$ & $7.00 \pm 1.69 \mathrm{a}$ & $7.14 \pm 1.22 \mathrm{ab}$ \\
\hline
\end{tabular}

mean \pm SD Different letters within the same column indicate significant differences $(p<0.05)$ 
Figure 1. Procedure for preparing sponge cakes

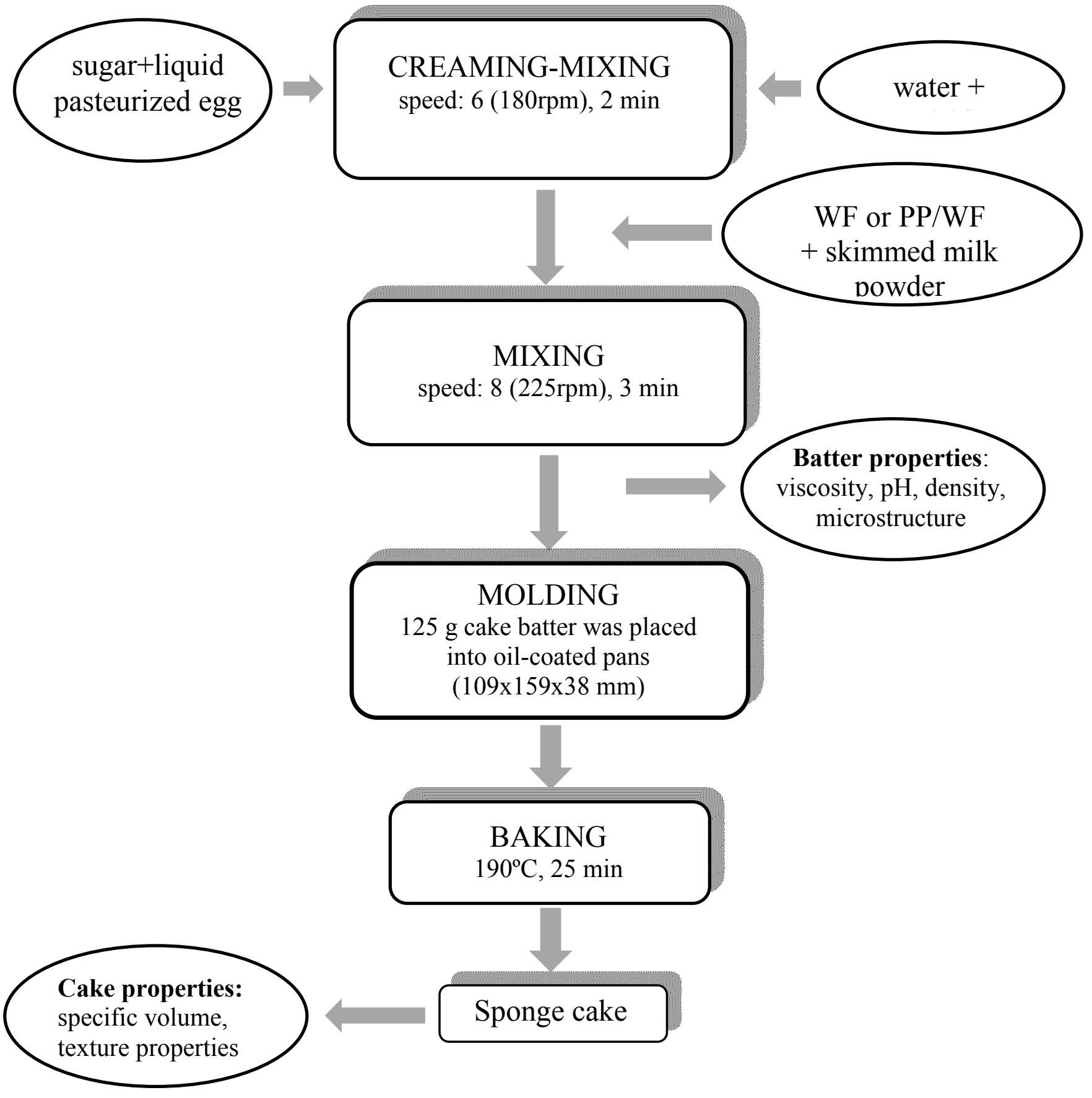


Figure 2. Procedure for preparing layer cakes

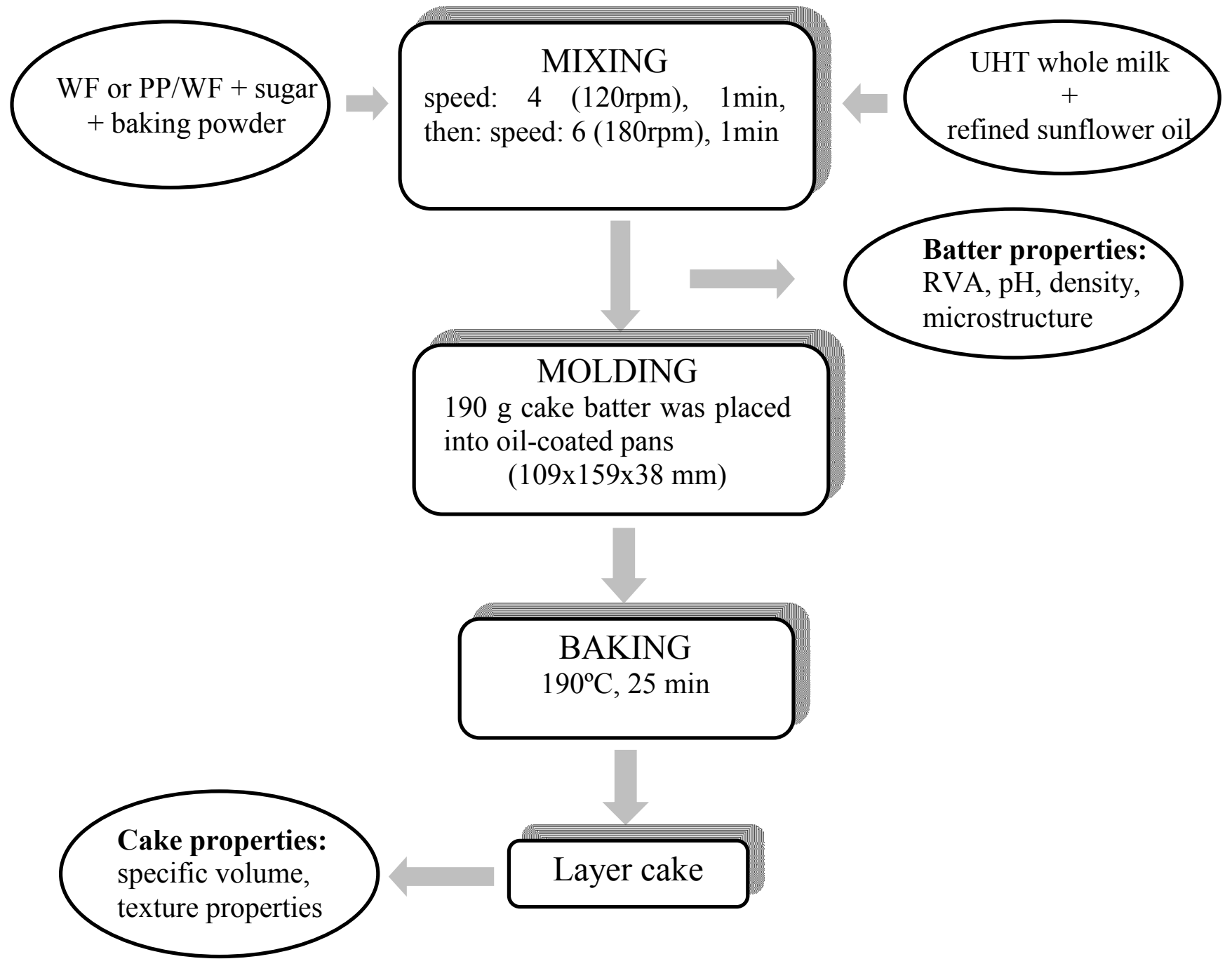


Figure 3. Micrographs of batters of sponge cakes: a) control; b) 15\% PP200; c) 15\% PP500; d) 15\% PP750; e) 30\% PP200; f) 30\% PP500; g) $30 \%$ PP455. PP: pear pomace particle; FP: flour particles; AB: air bubble. Bar $=20 \mu \mathrm{m}$

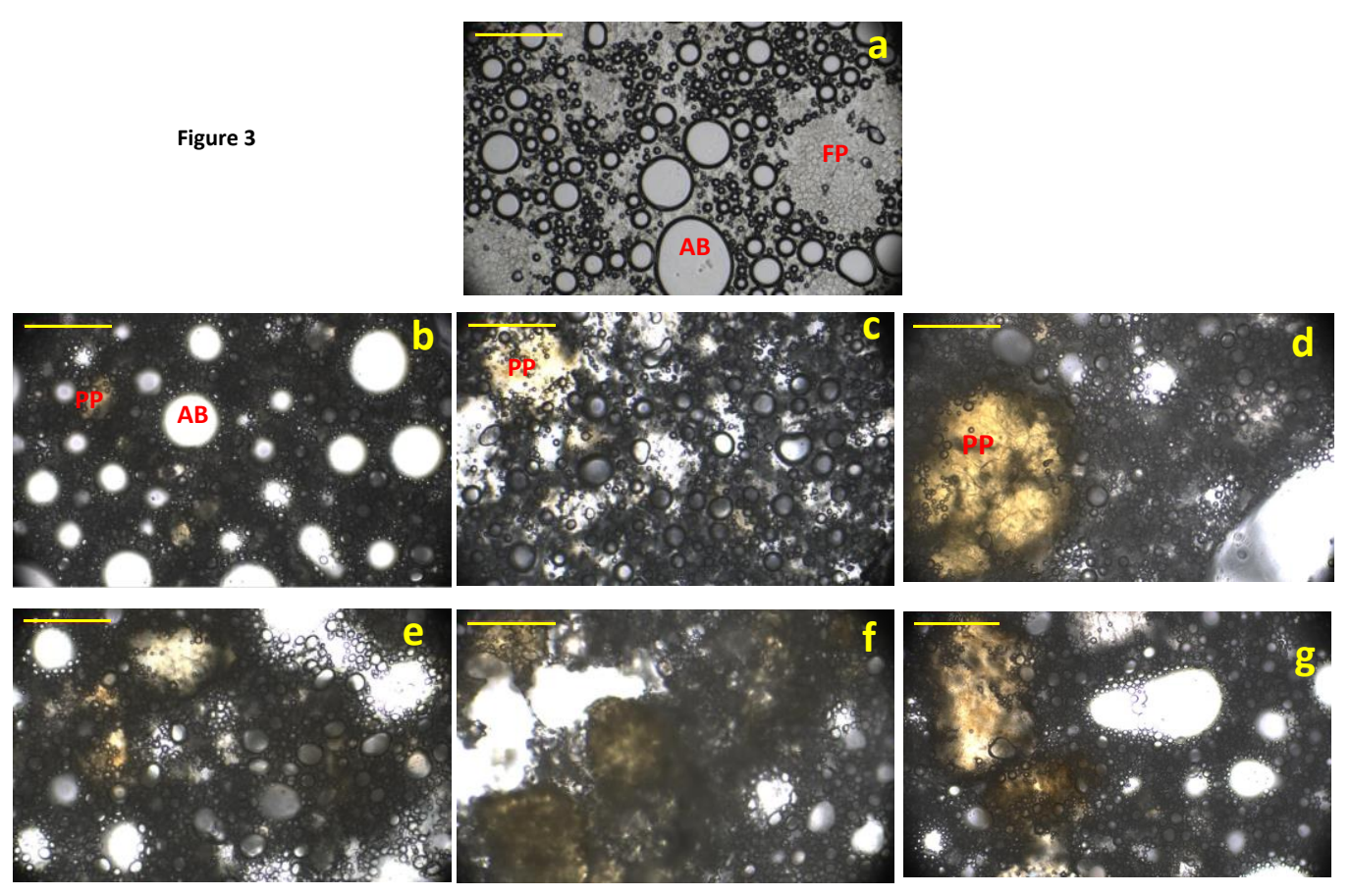


Figure 4. Micrographs of batters of layer cakes: a) control; b) 15\% PP200; c) 15\% PP500; d) 15\% PP750; e) 30\% PP200; f) 30\% PP500; g) 30\% PP750. PP: pear pomace particle; FP: flour particles; AB: air bubble. Bar $=20 \mu \mathrm{m}$

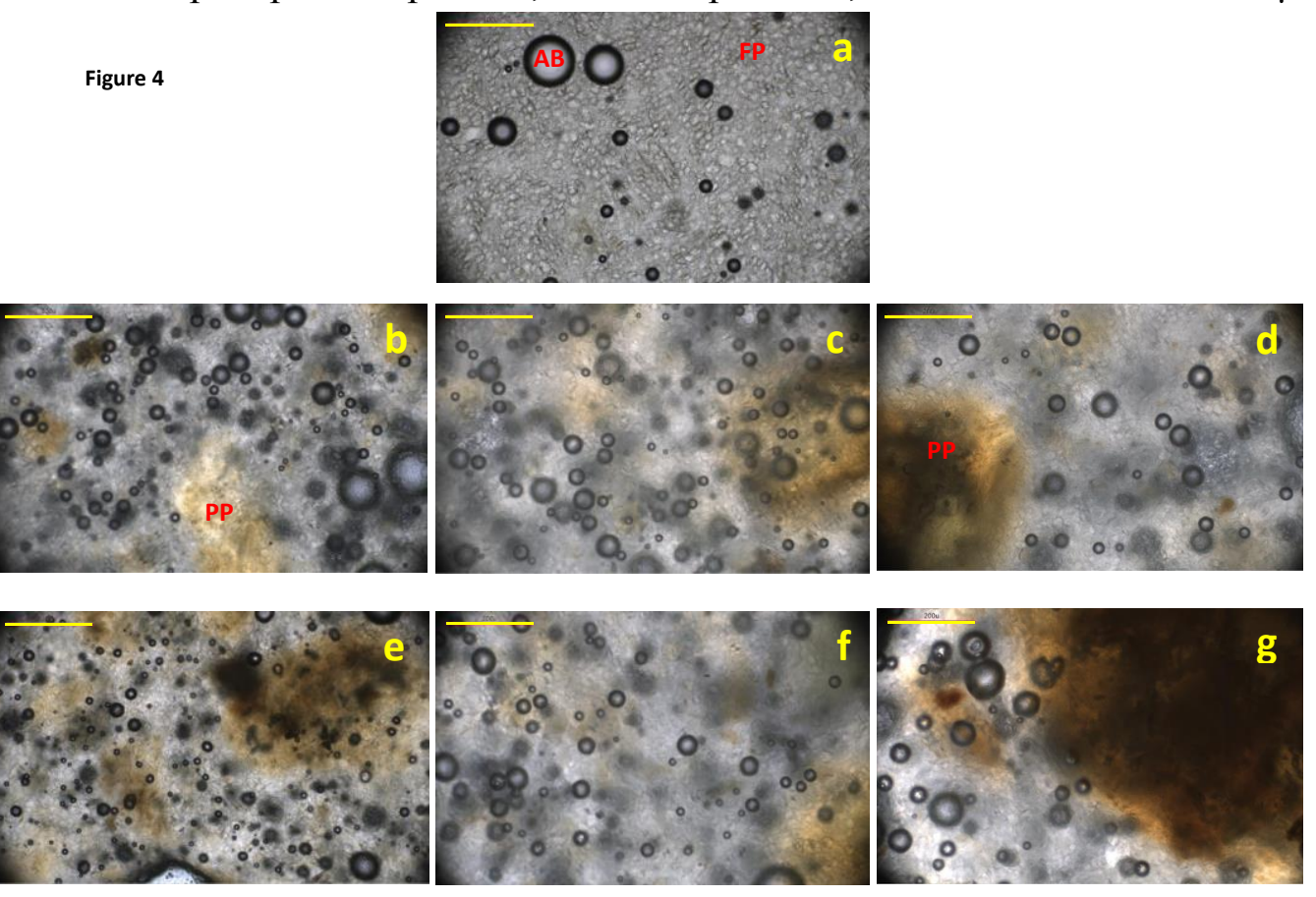


Figure 5. Slices of sponge cakes (a) and layer cakes (b) with different levels of replacement (15-30\%) and particle sizes of pear pomace-PP (200, 500 and $750 \mu \mathrm{m})$

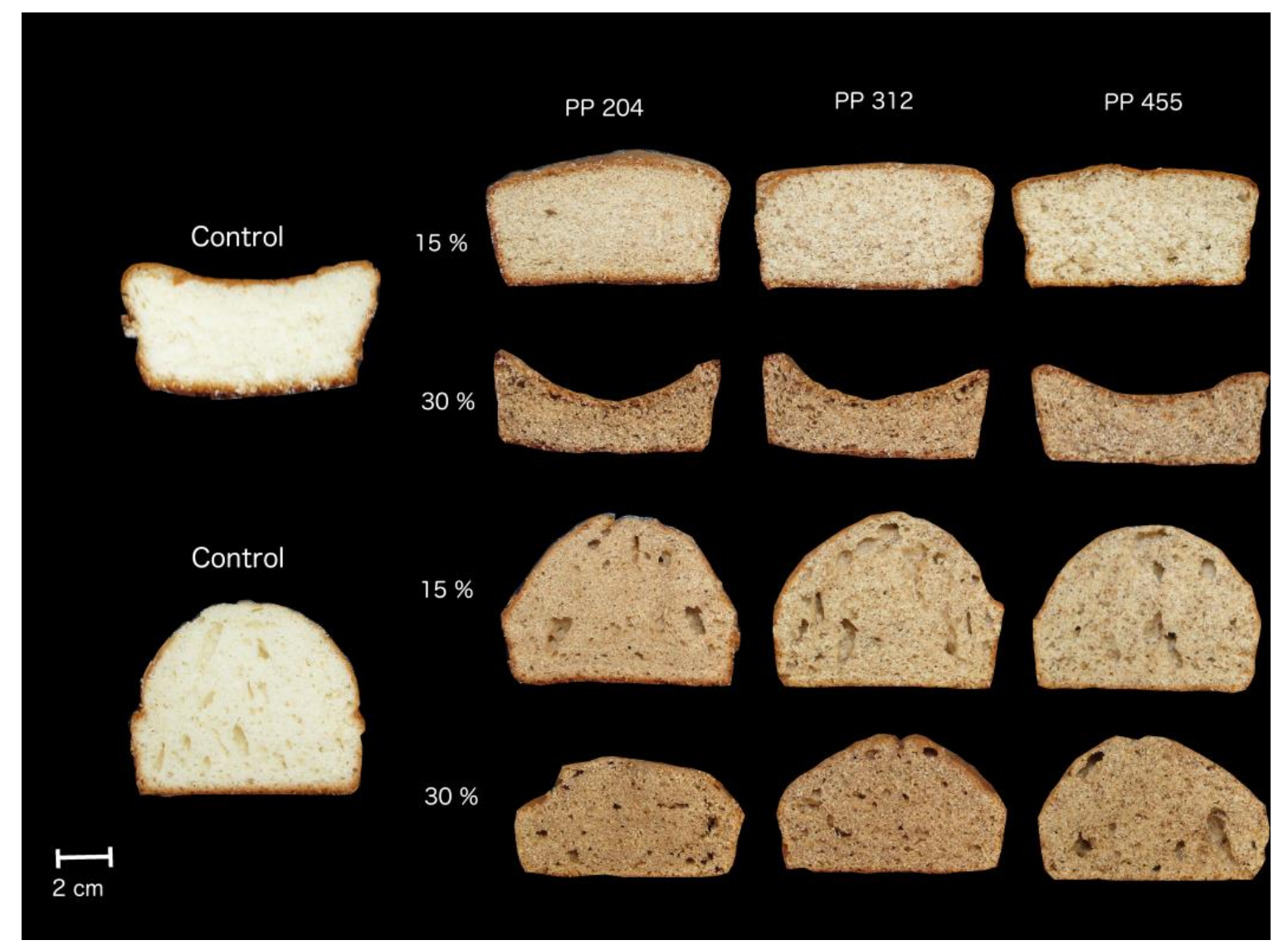


Figure 6. Texture attributes of sponge (light gray) and layer (dark gray) cakes as a function of the level of replacement (15-30\%) and particle sizes of pear pomace-PP $(200,500$ and $750 \mu \mathrm{m})$. Different letters above bars within the same series (sponge or layer) indicate significant differences $(\mathrm{p}<0.05)$
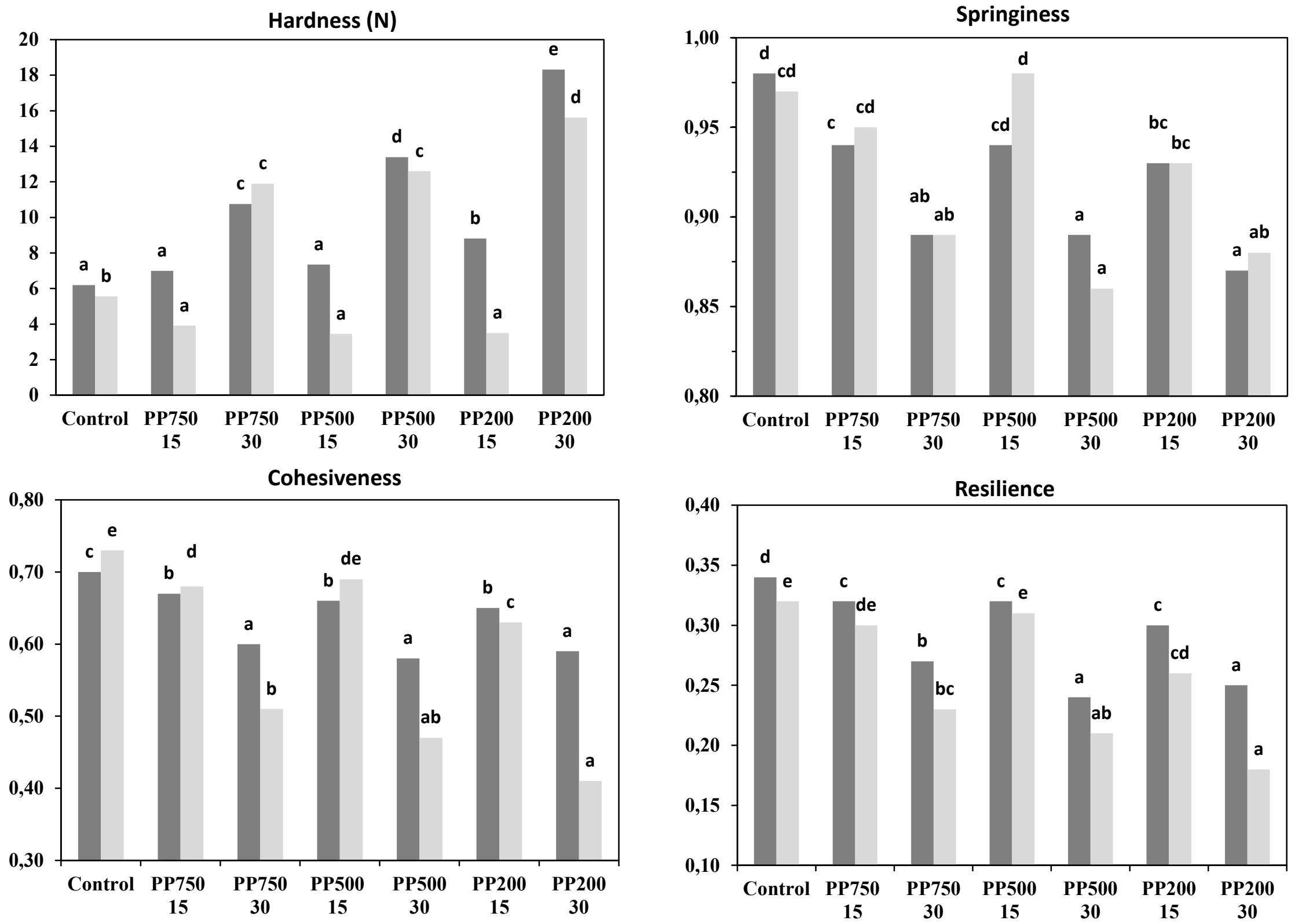